\title{
Design, synthesis and physico-chemical investigation of a dinuclear zinc(II) complex with a novel 'end-off' compartmental ligand
}

\author{
ANIL D NAIK and VIDYANAND K REVANKAR* \\ Department of Chemistry, Karnatak University, Dharwad 580 003, India \\ e-mail: vkrevankar@ rediffmail.com
}

MS received 17 March 2001; revised 9 July 2001

\begin{abstract}
A novel dinucleating pentadentate Schiff base, resulting from the condensation of 2,6-diformyl-p-cresol and N-methyl-indolyl-3-thiohydrazide, and its $\mathrm{Zn}$ complex have been prepared and characterized on the basis of elemental analysis, IR, UV-Visible, ${ }^{1} \mathrm{H}$ NMR and ${ }^{13} \mathrm{C}$ NMR studies. The ligand is acyclic and consists of a phenolate head unit, with two inbuilt azomethine shoulders and two indole thiohydrazide arms forming SNONS coordinating sites. NMR and IR spectral studies show that the ligand exists in thioketo form. Each $\mathrm{Zn}$ ion in the dinuclear core is in tetrahedral environment with endogenous phenolate bridging and exogenous acetate bridging. The zinc complex in DMF exhibits fluorescence.
\end{abstract}

Keywords. N-methyl-indolyl-3-thiohydrazone; compartmental ligand; Zn(II) complex of thiohydrazone; 2,6-diformyl- $p$-cresol.

\section{Introduction}

Phenol-based compartmental ligands of 'end-off' type, possessing two chelating arms attached to the 2- and 6-positions of the phenolate ring, have often been used to provide -phenoxo bridged dinuclear core complexes, keeping option for varying exogenous bridge ${ }^{1}$. Zinc-containing, carboxylate-bridged bimetallic centres are widespread structural motifs in hydrolytic metalloenzymes such as phosphatase and amino peptidases and some synthetic dinuclear $\mathrm{Zn}$ (II) complexes are found to have functions in RNA hydrolyse and dephosphorylation ${ }^{2-7}$.

Considerable research has been carried out on N/O multidentate ligands to mimic synthetic analogues of nitrogen-rich zinc enzymes ${ }^{8}$ but little is known about metal chelates of multidentate ligands having $\mathrm{N} / \mathrm{O} / \mathrm{S}$ donors, particularly those based on indole thiohydrazide moiety ${ }^{9-12}$. These observations were the impetus for us to build a thiohydrazide moiety on $\mathrm{N}$-methyl indole and extending its framework to construct compartmental ligand by condensing it with dicarbonyl compound and synthesize zinc complex to study its coordinating behaviour.

\section{Experimental}

2,6-Diformyl-p-cresol and N-methyl-indole-3-dithiocarboxylate were respectively synthesized by a slight modification of the literature method ${ }^{13-15}$. Reactions are outlined in scheme 1.

\footnotetext{
*For correspondence
} 

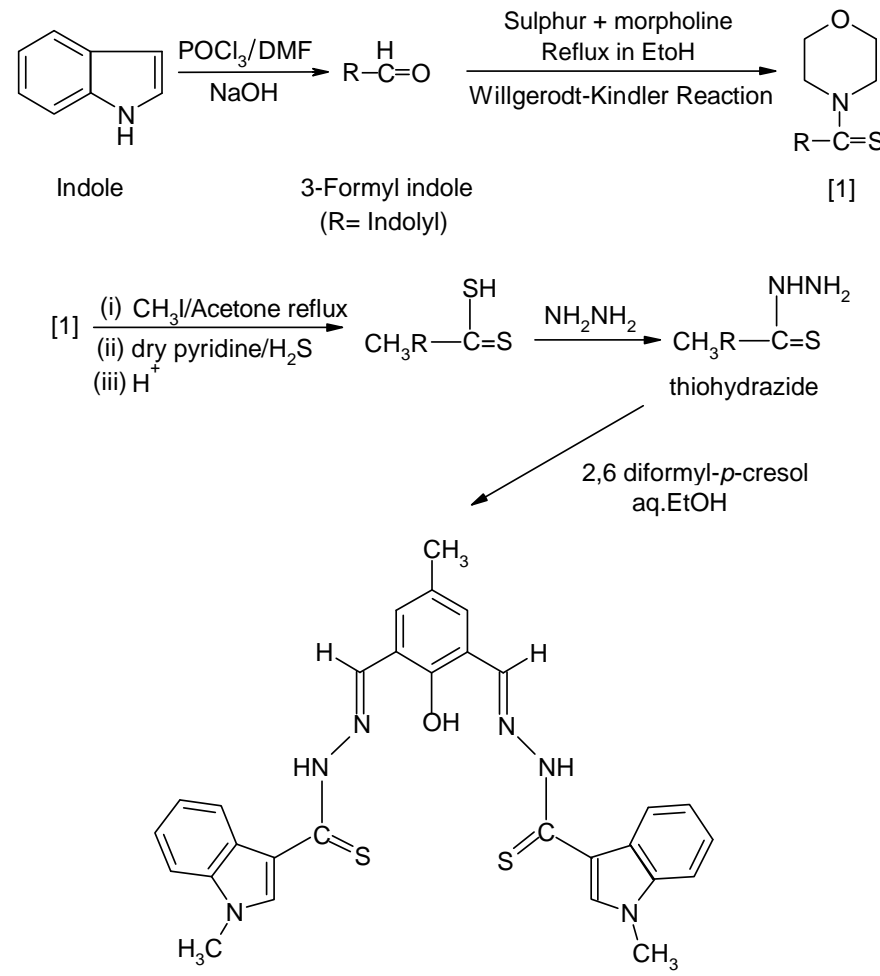

2,6-Diformyl-p-cresol-bis[N-methyl indolyl-3-thiohydrazone]

Scheme 1.

\subsection{Preparation of $\mathrm{N}$-methyl indolyl-3-thiohydrazide}

An ethanolic solution $\left(15 \mathrm{~cm}^{3}\right)$ of hydrazine hydrate $(0.68 \mathrm{~g}, 0.01$ mole) was slowly added with stirring to an ethanolic $\left(35 \mathrm{~cm}^{3}\right)$ solution of $\mathrm{N}$-methyl indole-3dithiocarboxylate $(2.07 \mathrm{~g}, 0.01 \mathrm{~mole})$. The mixture was refluxed for $1 \mathrm{~h}$ and then the clear solution allowed to cool to room temperature. The colourless crystals that separated were filtered, washed with $\mathrm{EtOH}$ and dried (yield $50 \%$, m.p. $160^{\circ} \mathrm{C}$ ).

\subsection{Preparation of 2,6 diformyl-p-cresol-bis[N-methyl indolyl-3-thiohydrazone]}

Thiohydrazide (4.38 g, 0.02 mole) and 2,6-diformyl-p-cresol (1.64 g, 0.01 mole) in aq. EtOH $\left(50 \mathrm{~cm}^{3}, 1: 1\right.$ by vol.) were refluxed for $1 \mathrm{~h}$. The pale yellow needles that crystallized out from the clear solution after cooling were filtered, washed with EtOH and dried in vacuo. Yield $80 \%$, m.p. $219^{\circ} \mathrm{C}$. Analysis: Calc. for $\mathrm{C}_{29} \mathrm{H}_{26} \mathrm{~N}_{6} \mathrm{OS}_{2}: \mathrm{C}, 64 \cdot 18$; H, 4.75; N, 15.88; S, 11.48\%. Found: C, 64.66; H, 4.86; N, 15.60; S, $11.91 \%$.

\subsection{Preparation of complex}

Zinc acetate $(0.439 \mathrm{~g}, 0.002$ mole $)$ in $\mathrm{EtOH}\left(15 \mathrm{~cm}^{3}\right)$ was added with stirring to an ethanolic solution $\left(20 \mathrm{~cm}^{3}\right)$ of the ligand $(0.538 \mathrm{~g}, 0.001 \mathrm{~mole})$ and refluxed for $2 \mathrm{~h}$. The 
dark yellow compound that precipitated was filtered, washed with $\mathrm{EtOH}$ and dried in vacuo. Analysis: Calc. for $\mathrm{Zn}_{2}\left(\mathrm{C}_{31} \mathrm{H}_{26} \mathrm{~N}_{6} \mathrm{O}_{3} \mathrm{~S}_{2}\right) .2 \mathrm{H}_{2} \mathrm{O}$ : C, 48.69; H, 3.79; N, 11.11; S, 8.42: Zn, 11.27\%. Found: C, 48.89; H, 3.97; N, 11.04; S, 8.42; Zn, 11.17\%.

\subsection{Physical measurements}

The complex was analysed for its metal content by EDTA titration after decomposition with a mixture of $\mathrm{HClO}_{4}$ and $\mathrm{HCl}$, followed by $\mathrm{HCl}$ alone. Sulphur was estimated as $\mathrm{BaSO}_{4}$. Carbon, hydrogen and nitrogen were estimated on a Thermoquest CHN analyser. Electronic spectra were recorded on a Hitachi 2001 spectrophotometer in DMF. Fluorescence study was done on an F-2000 Hitachi Fluorescence spectrophotometer. IR spectra were recorded in the $4000-400 \mathrm{~cm}^{-1}$ region ( $\mathrm{KBr}$ disc) on a Nicolet $170 \mathrm{SX}$ FTIR spectrophotometer. The ${ }^{1} \mathrm{H}$ and ${ }^{13} \mathrm{C}$ spectra were obtained in $d_{6}$-DMSO using TMS as an internal reference. $\mathrm{D}_{2} \mathrm{O}$ exchange is also recorded. Conductance measurements were determined in DMF using an Elico-CM82 conductivity bridge.

\section{Results and discussion}

The complex contains 2:1 metal to ligand ratio. It is formed by the loss of three protons. It is insoluble in water, $\mathrm{EtOH}$ and $\mathrm{MeOH}$ but is soluble in polar organic solvents such as DMF, DMSO and $\mathrm{CH}_{3} \mathrm{CN}$. Molar conductivities in DMF suggest that the complex is non-electrolytic.

\subsection{Electronic and fluorescence spectral studies}

Maxima at $250 \mathrm{~nm}$ and $275 \mathrm{~nm}$ in the case of the ligand are due to $\pi-\pi^{*}$ transitions. These bands are almost unchanged in the spectra of the complex. The ligand also shows a broad band at $325 \mathrm{~nm}$ with a shoulder at lower energy, due to the $n-\pi^{*}$ transition associated with the azomethine linkage. This band in the complex has shown a bathochromic shift due to the donation of a lone pair of electrons to the metal and hence the coordination of azomethine ${ }^{16-17}$. The broad shoulder centred around $365 \mathrm{~nm}$ in the ligand was assigned to $n-\pi^{*}$ of the thioamide chromophore which suffers a blue shift in the complex due to thioenolisation.

The moderately intense broad band for the complex in the region $350-425 \mathrm{~nm}$ is assigned to $\mathrm{S} \rightarrow \mathrm{Zn}$ (II) ligand to metal charge transfer transition (LMCT). The LMCT maxima for the phenolate complex shows line broadening, with a tail running into the visible part of the spectrum. This may result from a phenolate to $\mathrm{Zn}$ (II) LMCT band being superimposed on the low energy side of $S \rightarrow Z n$ (II) LMCT. Except this the complex shows no appreciable absorptions in the region above $450 \mathrm{~nm}$ in DMF solution, in accord with the $d^{10}$ electronic configuration of the $\mathrm{Zn}(\mathrm{II})$ ion.

Fluorescence spectra of the complex show (figure 1) a strong emission band at $486 \mathrm{~nm}$ when excited with $350 \mathrm{~nm}$ radiation, at room temperature with sample concentration of $0.1 \mathrm{mmol}$ in DMF. Generally fused-ring systems like indole and its derivatives show fluorescence. The free ligand shows an enhanced fluorescent intensity on complexation with diamagnetic zinc ion. The emission is neither MLCT (metal-to-ligand charge transfer) nor LMCT in nature. We tentatively assign it to the intraligand $\left(\pi-\pi^{*}\right)$ fluorescence, since a similar emission is also observed for the free ligand, but with reduced intensity. It is known that lone pairs of electron on nitrogen and on thioamide 


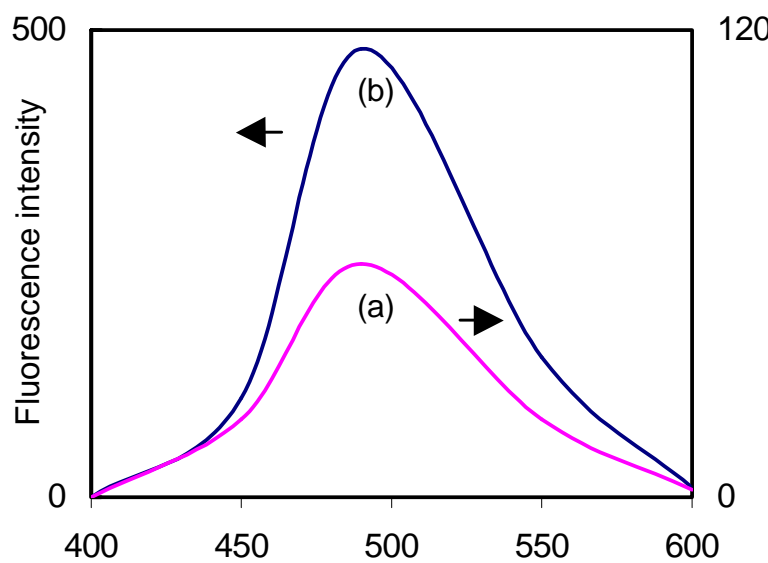

Figure 1. Fluorescence spectra of (a) free ligand (b) zinc complex $(0 \cdot 1 \mathrm{mmol})$ in DMF with excitation at $350 \mathrm{~nm}$.

chromophore can quench the fluorescence of indole moiety through photo-induced electron transfer ${ }^{18-21}$. Draining out of these pairs of electrons on to the metal orbital via complex formation causes a suppression of this fluorescence quenching and therefore results in increase in fluorescence intensity ${ }^{20}$. The formation of metal chelates with metal ions, in general, also promotes fluorescence by promoting rigidity and minimizing internal vibrations. At higher concentration $(1 \mathrm{mmol})$ the fluorescence intensity decreases considerably due to self-quenching.

\subsection{IR spectral studies}

The spectra of the ligand show a band of medium intensity at $3215 \mathrm{~cm}^{-1}$ which is assigned to $v(\mathrm{NH})$. Absence of any band around $2400-2600 \mathrm{~cm}^{-1}$ confirms that the ligand exists in thioketo form ${ }^{22} .{ }^{1} \mathrm{H}$ NMR further confirms this, which shows no signal for the SH group. The sharp band at $1618 \mathrm{~cm}^{-1}$ which was assigned to $v(\mathrm{C}=\mathrm{N})$ in the ligand has shifted to lower energy suggesting coordination of both the $\mathrm{N}$ atoms to metal. The $v(\mathrm{OH})$ broad band of the ligand around $3406 \mathrm{~cm}^{-1}$ has disappeared in the complex suggesting deprotonation of phenolic oxygen on coordination to metal.

In complex, the $v(\mathrm{NH})$ band disappears and there appears a weak band at $674 \mathrm{~cm}^{-1}$ assigned to $v(\mathrm{C}-\mathrm{S})$ stretching. Vibrational coupling among the thioamide groups are distributed at around 1535, 1422, 1374 and $749 \mathrm{~cm}^{-1}$ identified as thioamide bands I, II, III and IV in the ligand ${ }^{23}$. Bands at 1374 and $749 \mathrm{~cm}^{-1}$, which have major contribution from $v(\mathrm{C}=\mathrm{S})$, also appear in the complex but with reduced intensity. Asymmetric and symmetric stretching vibrations of the acetate group appear at $1585 \mathrm{~cm}^{-1}$ and $1442 \mathrm{~cm}^{-1}$ respectively. The difference between $v_{a s y m}(\mathrm{COO})$ and $v_{s y m}(\mathrm{COO})$ is $144 \mathrm{~cm}^{-1}$, which is smaller than $164 \mathrm{~cm}^{-1}$ observed in ionic acetate, reflects the bidentate bridging coordination mode ${ }^{3}$. A medium intensity band at $3339 \mathrm{~cm}^{-1}$ indicates presence of noncoordinated water. 


\section{$3.4{ }^{1} H$ NMR and ${ }^{13}$ C spectral studies}

Signals at 12.4 and $11.8 \mathrm{ppm}$ are due to $-\mathrm{OH}$ and $-\mathrm{NH}$ protons, which disappear on $\mathrm{D}_{2} \mathrm{O}$ exchange. Protons of $\mathrm{N}-\mathrm{CH}_{3}$ and $\mathrm{Ph}-\mathrm{CH}_{3}$ are observed at 3.35 and $2.31 \mathrm{ppm}$ respectively ${ }^{24,25}$ A singlet at $8.58 \mathrm{ppm}$ is due to the azomethine proton. A doublet around $7 \cdot 12 \mathrm{ppm}$ is due to protons adjacent to the $-\mathrm{CH}_{3}$ in the $p$-cresol moiety and the protons of the pyrrole ring of indole. Protons of the phenyl ring of indole are found between 7.46 to $8.25 \mathrm{ppm}$. The signals at $20,40,143,147$ and $160 \mathrm{ppm}$ in ${ }^{13} \mathrm{C}$ spectra are due to carbons of the $-\mathrm{CH}_{3}, \mathrm{~N}-\mathrm{CH}_{3},-\mathrm{C}=\mathrm{N},-\mathrm{C}-\mathrm{OH}$ and $-\mathrm{C}=\mathrm{S}$ groups respectively ${ }^{24,26-28}$. In the $\mathrm{Zn}$ complex, signals due to $-\mathrm{OH}$ and $-\mathrm{NH}$ are absent, supporting deprotonation and thioenolisation. Signals due to the protons of the phenyl ring of the indole show splitting. This may be due to the dissymmetry caused by the non-planarity of the ligand on complexation $^{25}$. The $0 \cdot 11-\mathrm{ppm}$ downfield shift of the acetate resonance $(\delta 1.99)$ compared with that of the ionic acetate $\left(\mathrm{CH}_{3} \mathrm{COONa}, \delta 1 \cdot 88\right)$ suggests interaction of the acetate with the metal centres in solution.

\section{Conclusions}

In this communication, an attempt is made to bring together a dicarbonyl moiety, which provides a backbone for the compartmental ligand, the pharmacologically active indole thiohydrazide and the biologically active zinc ion. The proposed structure of the complex is given in figure 2. By synthesizing these compounds, we are heading towards the designing of synthetic models of sulphur-rich zinc enzymes. Magnetic studies with other transition metal complexes, particularly of copper with this ligand and varying exogenous bridges, may provide some insight into the magnetic environment around the metal ion and the nature of the magnetic exchange interaction between the metal centres. Enhancement of fluorescence behaviour upon complexation can be utilised for analytical applications.

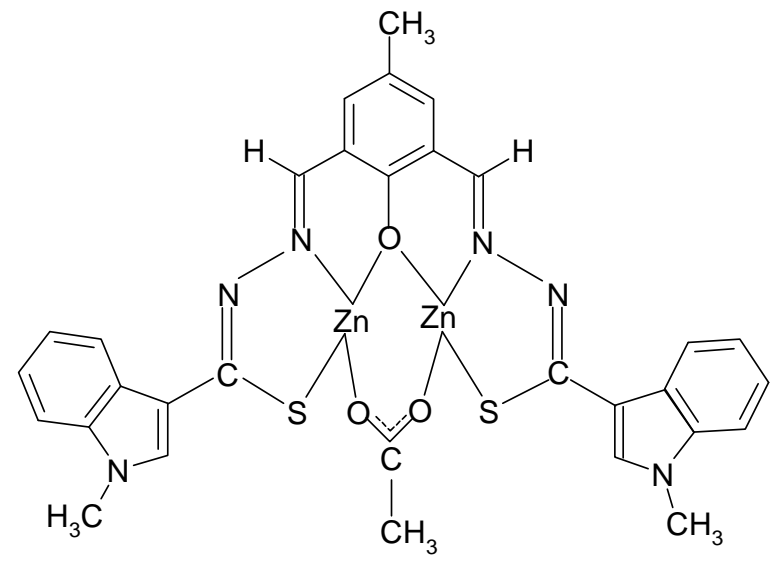

Figure 2. Proposed structure of the complex. 


\section{Acknowledgements}

The authors thank the University Science Instruments Centre, Karnatak University, Dharwad for providing spectral facilities and CHN analysis. We also thank ASTRA IDL, Bangalore for recording ${ }^{1} \mathrm{H}$ and ${ }^{13} \mathrm{C}$ NMR spectra. One of the authors (ADN) thanks the Karnatak University for a fellowship.

\section{References}

1. Guerriero P, Casellato U, Ajo, Sitran S and Vigato P A 1988 Inorg. Chim. Acta 142305

2. Brooker S and Davidson T C 2000 Inorg. Chim. Acta 306227

3. Asato E, Furutachi H, Kawahashi T and Mikuriya M 1995 J. Chem. Soc., Dalton Trans. 3897

4. Erxleben A and Hermann J 2000 J. Chem Soc., Dalton Trans. 569

5. Andrea E and Jolante H 2000 J. Chem. Soc., Dalton Trans. 569

6. Bazzicalupi C, Bencini A and Valtancoli B 1999 Inorg. Chem. 384155

7. Sakiyama H, Mochizuki R, Sugawara A, Sakamoto M, 1999 J. Chem. Soc., Dalton Trans. 997

8. Parkin G 2000 Chem. Commun. 1971

9. Kamalendu D and Debaish B 1999 J. Indian Council Chemists 1636

10. Biswas P K and Chaudhuri N R 1981 J. Chem Soc., Dalton Trans. 2385

11. Band U and Vahrenkamp H 2000 Inorg. Chim. Acta 30897

12. Marchetti F, Pettinari C, Pettinari R, Cingolani A, Leonasi D and Lorenzotti A 1999 Polyhedron 183041

13. Denton A and Suschitzky H 1963 J. Chem. Soc. 4741

14. Smith G F 1954 J. Chem. Soc. 3842

15. Doyle F P, Ferrier W, Holland D O, Mehta M and Nayler J H C 1956 J. Chem. Soc. 2853

16. Bhardwaj N C and Singh R V 1994 Proc. Indian Acad. Sci. (Chem. Sci.) 10615

17. Ainssough E W, Brodie A M, Rangford J and Waters J M 1997 J. Chem Soc., Dalton Trans. 279

18. James T, Linnane P and Shinkai S 1996 Chem. Commun. 281

19. Yoon J and Czarnik A W 1992 J. Am. Chem. Soc. 1145874

20. Wang Wei, Springsreen G, Shouhai G and Wang Binghe 2000 Chem. Commun. 1283

21. Burgemeister T, Grobe-Einster R, Grotstollen R, Mannschreck A and Wulff G 1981 Chem. Ber. 1143403

22. Choudhary R K, Yadav S N, Tiwari H N and Mishra L K 1998 J. Indian Chem. Soc. 75392

23. Jensen K A and Nielsen P H 1966 Acta Chem. Scand. 20597

24. Richard G P and John R 1970 J. Org. Chem. 351970

25. Shetty U N, Revankar V K and Mahale V B 1997 Proc. Indian Acad. Sci. (Chem. Sci.) 1097

26. Vogel A I Text book of practical organic chemistry 5th edn (London: ELBS) pp 1424, 1434

27. Singh N K, Kushawaka S K and Dixit A K 2000 Synth. React. Inorg. Met-Org. Chem. 301237

28. Singh N K, Srivastava A, Sodhi A and Ranjan P 2000 Transition Metal Chem. 25133 